\title{
Acute Appendicitis with Septic Shock as the First Symptom: A Case Report
}

\author{
Bailang Chen*, Li Xu \\ Department of Emergency Medicine, The seventh affiliated hospital of Sun Yat-sen University, China
}

Submission: February 06, 2020; Published: February 20, 2020

*Corresponding author: Bailang Chen, Department of Emergency Medicine, The seventh affiliated hospital of Sun Yat-sen University. No. 628, Zhenyuan Road, Guangming District, Shenzhen, China

\section{Introduction}

Acute appendicitis is characterized by pain in the right lower abdomen. The patient's physical examination is mainly tenderness in the right lower abdomen. Acute appendicitis with septic shock as the first symptom is rare. Especially for patients with atypical abdominal signs, it is easy to mislead clinicians and delay treatment. We recently received a patient with septic shock as the main symptom. The patient's symptoms were atypical, and the treatment was delayed. Finally, peritonitis occurred. The patient turned to safety after emergency surgery. This article reviews the case to summarizing relevant experiences and improving the level of diagnosis and treatment.

\section{Case report}

Our patient is a Middle-aged, previously healthy, person who presented to the Emergency Department with a chief complaint of Back pain. Physical examination showed Renal throbbing pain. Vital signs at presentation were temperature of $38.8^{\circ} \mathrm{C}$, heart rate of $105 / \mathrm{min}$, respiratory rate of $22 / \mathrm{min}$ and blood pressure of $74 / 58 \mathrm{~mm} / \mathrm{Hg}$. Ultrasound of urinary system shows kidney stones. The patient was diagnosed with septic shock. Imipenem was given anti-infection (1g q12h), and norepinephrine was used to maintain blood pressure. The patient's symptoms gradually improved. Blood routine tested showed a leukocyte count of $4.55 \times 10^{\wedge} 9 / \mathrm{L}$, with $90.8 \%$ neutrophils, and CRP $41.18 \mathrm{mg} / \mathrm{L}$, PCT $33.64 \mathrm{ng} / \mathrm{ml}$. Cardiopulmonary examination was negative. No obvious tenderness in the abdomen. In the early morning of the next day, the patient suddenly developed total abdominal pain. On examination, the abdominal muscles were tense, and tenderness and rebound pain were obvious. WBC was elevated at $26.43 \times 10^{\wedge} 9 / \mathrm{L}$ with $92.2 \%$ neutrophils, and CRP:171.02mg/L, PCT $90.94 \mathrm{ng} / \mathrm{ml}$. Abdominal CT suggestion: Appendicitis and periappendicitis with peripheral exudation (Figure 1 \& 2). Patient's condition gradually stabilizes after emergency appendectomy.
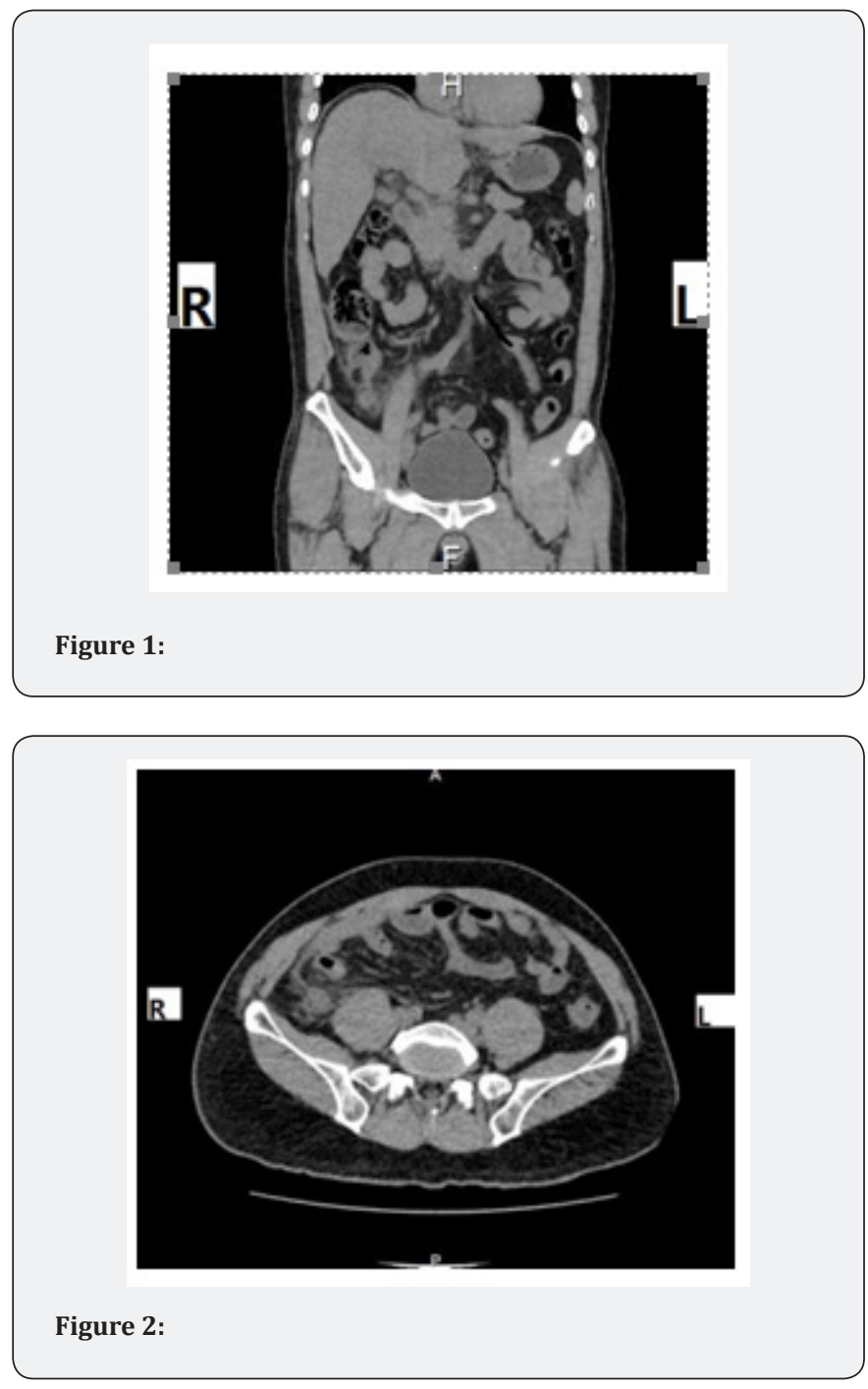


\section{Discussion}

Appendicitis is very common in hospitals, and most of them have typical clinical symptoms. However, acute appendicitis with shock as the first symptom is rare [1]. Due to the complex causes of shock, sometimes the primary disease is more difficult to find. For patients who are shocked when they are admitted to the hospital, we must find the original cause of shock while anti-shock. According to the cause of shock, we divide shock into the following categories: cardiogenic shock, septic shock, hemorrhagic shock, etc. For cardiogenic and hemorrhagic shock, a clear diagnosis can often be made through past history and cardiac ultrasound. However, for patients with septic shock, sometimes the cause is difficult to determine, especially when the patient's symptoms and signs are not obvious, and it is often easy to delay treatment. For patients with septic shock. Finding the source of infection and clearing the infection as early as possible is the key to rescue patients. However, it is often difficult to quickly locate the source of infection due to systemic inflammation and comorbidities. At this time, careful inquiry of the patient's medical history becomes extremely important. In this case, the patient did not show obvious symptoms of pain in the right lower abdomen after admission, and there were no obvious signs on his abdominal examination. No ectopic appendix was found during the operation. The patient's preoperative blood pressure is low, and the infection index is high, suggesting that the patient's condition is severe at this time [2]. The patient showed more obvious waist pain when admitted to hospital, which made us divert attention to urinary infection. The final abdominal CT results suggest that the cause of back pain is kidney stones. The appendix area does not show obvious signs. Considering the following two reasons: a) The patient took antibiotics before admission to control inflammation

b) The patient's abdomen was slightly swollen, and the position of the appendix was too deep so that the inflammation had not spread to the membrane.

Therefore, for patients admitted to the emergency department, obvious pain may not be the main cause, and we cannot ignore those potential or even minor pain. For patients admitted to hospital with septic shock as the first symptom, we need to find the infection as soon as possible to avoid delay in treatment. Therefore, for patients whose infection site is not very clear, in order to identify the causative factors as soon as possible, chest and abdominal CT examination is often necessary. Among appendicitis, ectopic appendicitis is not uncommon, and clinical manifestations are often not typical [3]. At this time, CT is a better method for diagnosis [4]. Before the relevant imaging examination, a detailed examination and medical history inquiry can help us find clues to the disease.

\section{References}

1. Zhen JP, Yuan XX, Chen LL (2008) Nursing experience of 1 case of septic shock caused by acute gangrenous appendicitis. Modern Journal of Integrated Traditional Chinese and Western Medicine 2008(11): $1755-1756$

2. SOPER, David E (2012) Early Recognition of Serious Infections in Obstetrics and Gynecology. Clin Obstet Gynecol 55(4): 858-863.

3. Akbulut Sami, Ulku A, Senol A, Tas M, Yagmur Y (2010) Left-sided appendicitis: Review of 95 published cases and a case report. World J Gastroenterol 16(44): 5598-5602.

4. Owen Smith M S (2010) Acute left-sided appendicitis. 56(3): 233-234.
Your next submission with Juniper Publishers will reach you the below assets

- Quality Editorial service

- Swift Peer Review

- Reprints availability

- E-prints Service

- Manuscript Podcast for convenient understanding

- Global attainment for your research

- Manuscript accessibility in different formats

( Pdf, E-pub, Full Text, Audio)

- Unceasing customer service

Track the below URL for one-step submission https://juniperpublishers.com/online-submission.php 